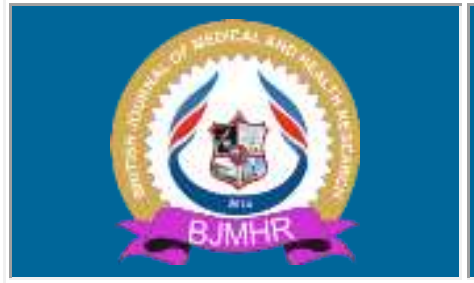

\title{
BJMHR
}

British Journal of Medical and Health Research Journal home page: www.bjmhr.com

\section{Urothelial Carcinoma with Sarcomatoid Differentiation of The Urinary Bladder- A Rare Case Presentation}

\author{
Sumbul Warsi, Shafaque Zabin, Mohd Talha, Kafil Akhtar* \\ Department of Pathology, Jawaharlal Nehru Medical College, Aligarh Muslim University, \\ Aligarh (U.P)-India.
}

\begin{abstract}
The spectrum of the bladder cancer is quite diverse, with urothelial cancer making up the majority of the cases. Urothelial carcinoma represents more than $90.0 \%$ of bladder cancers. Most cases of urothelial carcinoma of the bladder present in patients over the age of 50 years. We present a case report of a 47 year old male, who presented with complaints of blood in urine for one and a half months. CT-Scan showed an endophytic mass lesion involving left posterolateral wall of urinary bladder and left vesicoureteric junction. He was operated upon and was diagnosed as high grade urothelial carcinoma with sarcomatoid differentiation on histopathogical examination. Our patient was administered adjuvant chemotherapy, cisplastin $50 \mathrm{mg} / \mathrm{m}^{2} \times 6$ cycles. He is doing well after 6 months of follow up period.
\end{abstract}

Keywords: Urinary Bladder, Urothelial, Hematuria, Histopathology, Immunohistochemistry 


\section{INTRODUCTION}

Bladder cancer is the seventh most commonly diagnosed cancer seen in males worldwide. ${ }^{1}$ It drops to 11th when both males and females are accounted. The age-standardised incidence rate for men and women is 9.0 and 2.2 globally. ${ }^{1}$ Heamturia is a major presenting symptom and its awareness can lead to early diagnosis, individualized treatment and follow-up and key to a successful outcome. ${ }^{2}$ Bladder Carcinoma presents with a disease either confined to the mucosa (stage Ta, CIS) or submucosa (stage T1) in approximately $75.0 \%$ of the cases. ${ }^{2}$

The spectrum of bladder cancer is quite distinctive with majority of the cases comprising of urothelial cancer. ${ }^{3}$ Urothelial cancer is $90 \%$ of all the bladder cancers and mostly found in its pure form. Urothelial cancer shows variant histologic features, known as divergent differentiation, seen in $7.0 \%$ to $81.0 \%$ cases. $^{4,5}$ The variants of invasive urothelial carcinoma are squamous differentiation, glandular differentiation, nested pattern, microcystic, micropapillary, lymphoepithelioma-like, plasmacytoid and lymphoma-like, sarcomatoid/carcinosarcoma, giant cell, trophoblastic differentiation, clear cell, lipid cell and undifferentiated. ${ }^{4}$

\section{CASE SUMMARY}

A 47 year old male presented to the Surgical OPD with complaints of blood in urine for one and a half months. CT-Scan showed an endophytic mass lesion involving left posterolateral wall of urinary bladder and left vesicoureteric junction. Clinical diagnosis of urinary bladder mass with vesicoureteric junction involvement was made. Our patient underwent transurethral resection of bladder tumor.

Grossly, the resected mass was multiple, creamish brown, soft and measured $2 \times 1.8 \mathrm{cms}$ in size. On microscopy, foci of dysplastic urothelium with irregular nests of atypical tumor cells infiltrating the stroma with muscle fibres was seen. The tumor cells were moderately pleomorphic with round to ovoid vesicular nuclei and prominent nucleoli. Foci of atypical plump to spindle shaped tumor cells in fascicles were also seen with surrounding stromal lymphocytic response (Figure 1 and 2). On immunohistochemistry, tumor cells showed showed diffuse cytoplasmic positivity for CK7 (Figure 3) and the spindle cells showed focal cytoplasmic positivity for vimentin (Figure 4). A histopathological diagnosis of high grade urothelial carcinoma with sarcomatoid differentiation was given. Patient was administered adjuvant chemotherapy, cisplatin $50 \mathrm{mg} / \mathrm{m}^{2}$ x 6 cycles. Our patient is doing well after 6 months of follow up period. 


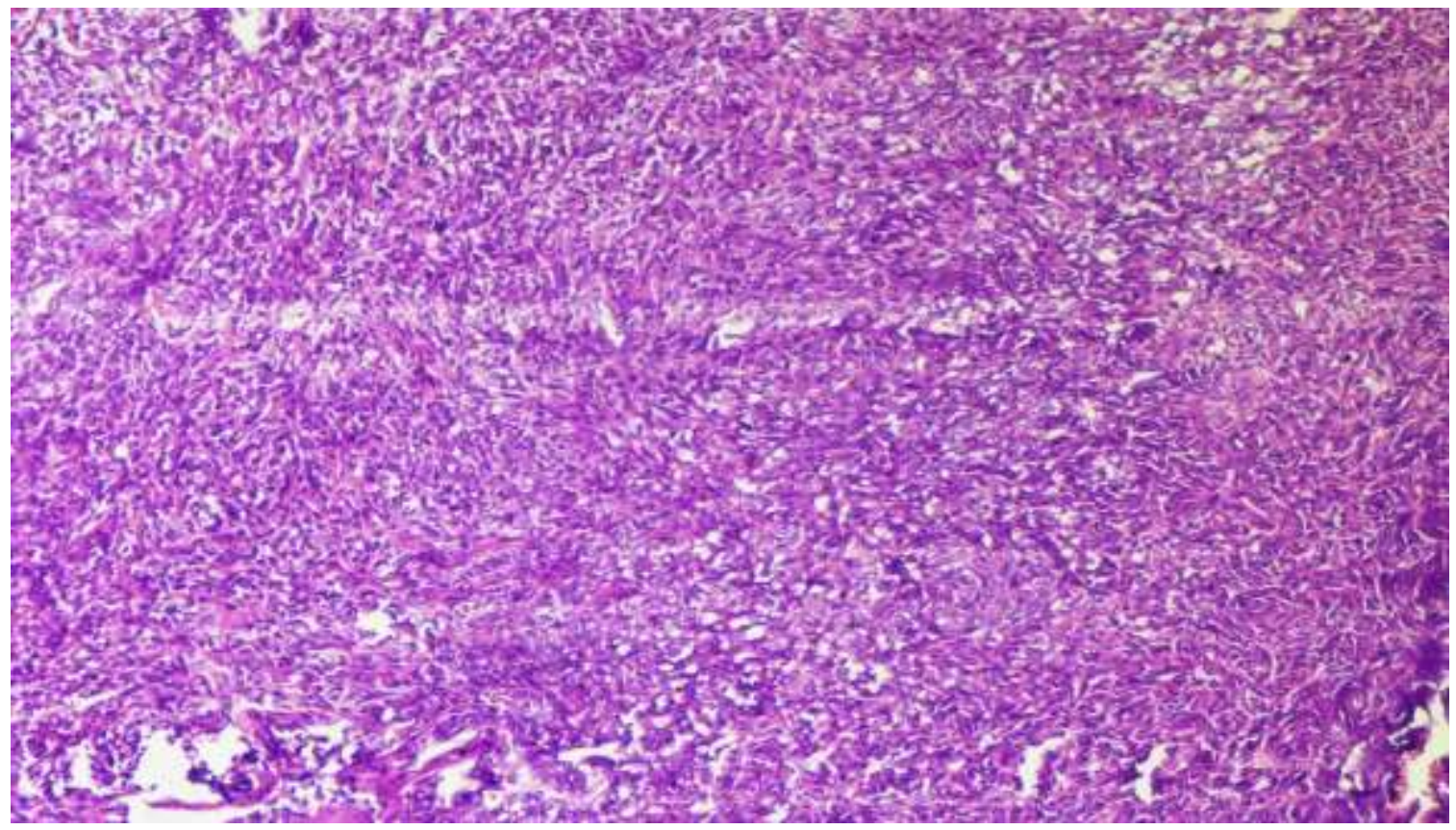

Figure 1: Tissue section showed foci of dysplastic urothelium with irregular nests of atypical tumor cells infiltrating the stroma with muscle fibres. Foci of atypical plump to spindle shaped tumor cells in fascicles were also seen with surrounding stromal lymphocytic response. Haematoxylin and Eosin $\mathrm{x} 10 \mathrm{X}$

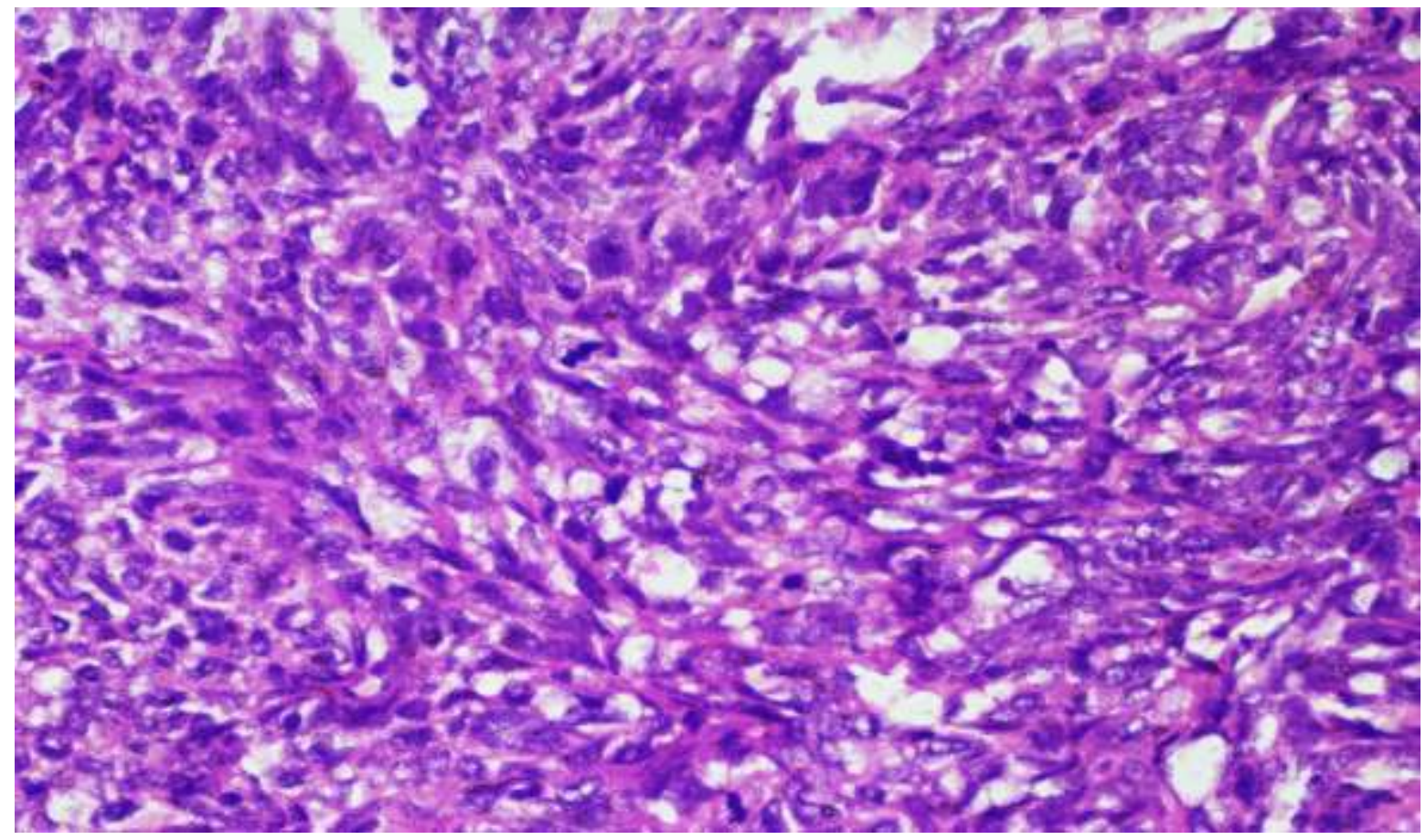

Figure 2: The tumor cells were moderately pleomorphic with round to ovoid vesicular nuclei and prominent nucleoli. Haematoxylin and Eosin x 40X 


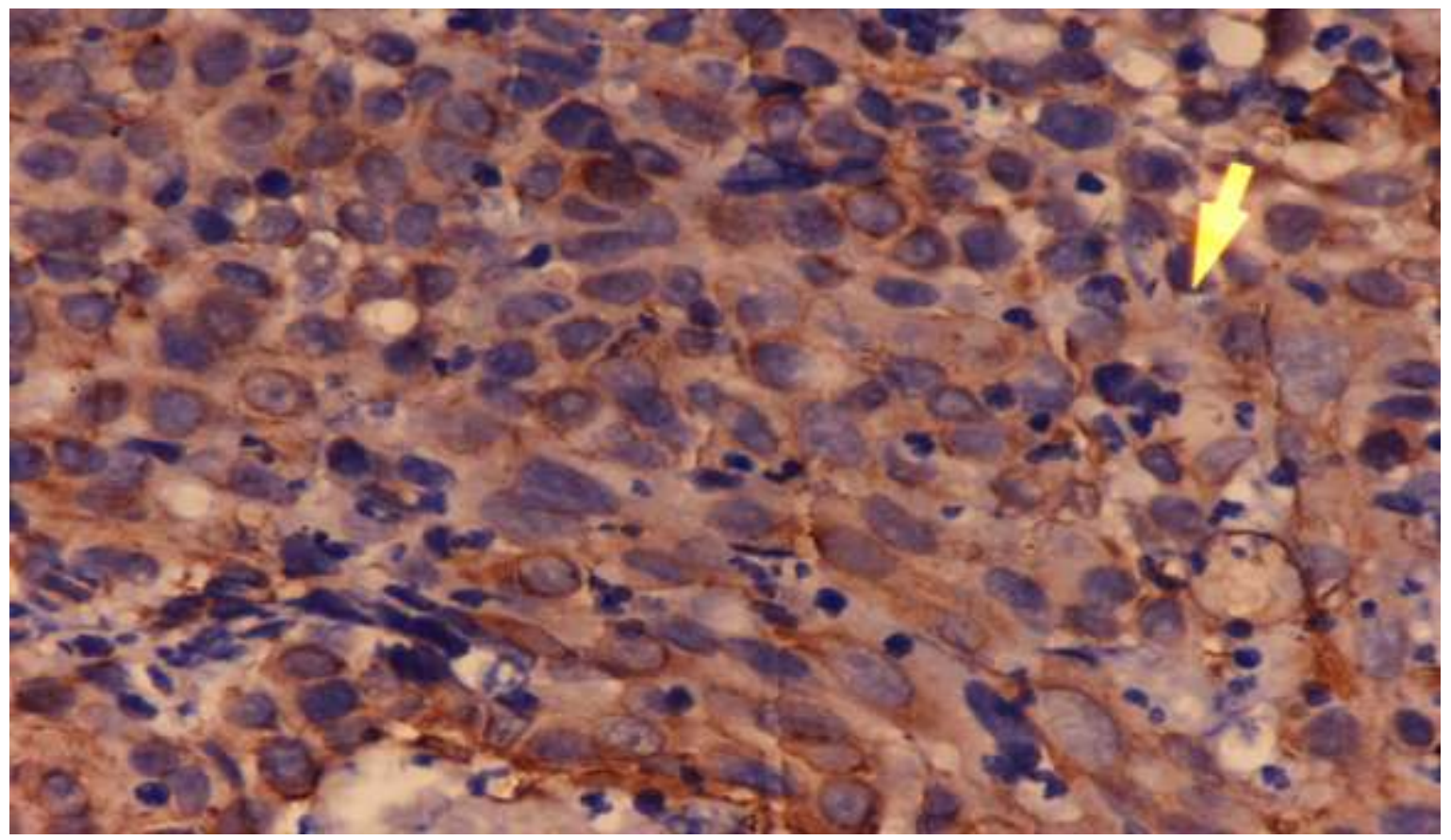

Figure 3: On immunohistochemistry, tumor cells showed showed diffuse cytoplasmic positivity for Cytokeratin7. IHC CK7x 40X.

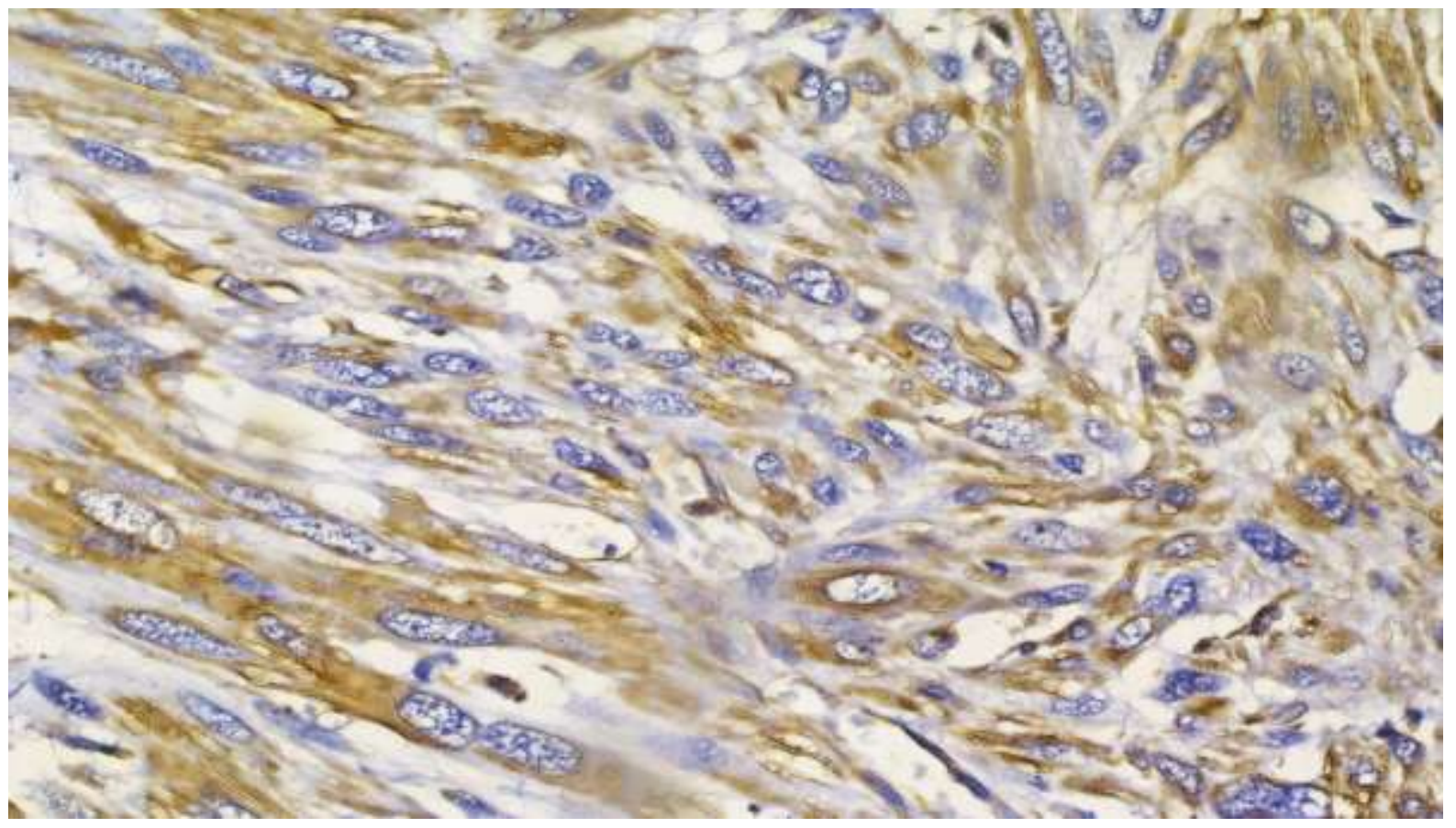

Figure 4: Immunohistochemical expression of Vimentin on the spindle cells showed focal cytoplasmic positivity. IHC Vimentin $\mathrm{x} 40 \mathrm{X}$.

\section{DISCUSSION}

Urothelial carcinoma (UC) shows a wide range of clinical features and morphology. It has a peculiar capacity for divergent histologic differentiation into the entire spectrum of histologic variants such as squamous, glandular, sarcomatoid, small cell, micropapillary, clear cell, lymphoepithelial, and plasmacytoid components. ${ }^{6-8}$ The UC should be classified with the type of differentiation observed if any divergent differentiation is seen together with the usual UC. ${ }^{7,8}$ 
Sung et al supported monoclonal cell origin of sarcomatoid carcinoma and suggested that clonal divergence may occur during tumour progression and differentiation by demonstrating identical pattern of non-random X-chromosome inactivation and significant overlap of loss of heterozygosity in both carcinomatous and sarcomatous components. ${ }^{9}$

In most of the cases, the epithelial component is urothelial carcinoma with squamous or glandular differentiation and the mesenchymal element was poorly or undifferentiated spindle cells with or without heterologous elements. ${ }^{10,11}$ Our case showed a predominant component of plump to spindle shaped cells. Immunohistochemistry is able to assist in determining cell lineage, with epithelial elements reacting with cytokeratins, whereas mesenchymal components react with vimentin and other markers corresponding to the specific mesenchymal differentiation.

It is hard to make a decision when early aggressive cystectomy should be performed, making the management quite challenging. ${ }^{12}$ The reference standard for the muscle-invasive tumors (radical cystectomy) is inadequate as a single therapy. ${ }^{13}$ Such patients may have a better survival by the use of neoadjuvant therapy. ${ }^{13,14}$ Following factors are likely to be associated with aggressive disease, tumor multifocality, tumor size greater than $5 \mathrm{~cm}$, associated CIS, involvement of the prostate and lymphovascular invasion. ${ }^{13,14}$

Treatment for most of the low grade and Ta superficial urothelial carcinoma is local resection of the tumor with close observation or intravesical therapy, whereas more aggressive treatment including cystectomy and/or radiation or chemotherapy are often done in patients with highgrade or T1 tumors who have a greater chance to progress to deeply invasive cancer with a much higher mortality rate. ${ }^{15,16}$ However, the tumor grade and stage have limited ability to predict tumor progression. ${ }^{14}$ But, there is a relatively low incidence of sarcomatoid variant and hence, no randomised controlled trials have been conducted by far to dictate optimal management for such tumours. The existing literature is reliant on case series, and there are limited systemic options available following local treatment with no consensus regarding the best treatment option. ${ }^{17}$

A study by Robinson et al have shown that carcinosarcoma did not have a worse prognosis than a classic high-grade urothelial carcinoma. There was no significant difference in grade, stage, positive surgical margin, lymph node involvement, associated prostate cancer or progression incidence rate, all-cause mortality, or by disease. However, carcinosarcomas represent three times the volume of urothelial cell tumors, which can contribute to its reputation as an aggressive tumor and the sarcomatous elements do not seem to confer a worse prognosis. ${ }^{18}$ 


\section{CONCLUSIONS}

Urothelial carcinoma with mixed histologic features identified at transurethral resection of bladder tumor portends a locally aggressive and advance disease. Any amount and type of divergent differentiation appears to be significant and therefore should be reported. Patients with mixed histologic features might benefit from an aggressive treatment strategy.

\section{REFERENCES}

1. Ferlay J, Soerjomataram I, Ervik M, Dikshit R, Eser S, Mathers C. GLOBOCAN 2012: Estimated cancer incidence, mortality and prevalence worldwide in 2012.

2. Uchida K and Shiraishi T. Urinary tract tumors. Rinsho Byori 2014; 62: 586-595.

3. Burger M, Catto JW, Dalbagni G. Epidemiology and risk factors of urothelial bladder cancer. Eur Urol 2013; 63:234-241.

4. Reuter VE. The urothelial tract: renal pelvis, ureter, urinary bladder, and urethra, in Mills SE edn: Sternberg's Diagnostic Surgical Pathology. Philadelphia, Lippincott, Williams \& Wilkins, 2014; pp 2035-2082.

5. Sanchia S, Raj P, Hanif M, David A. Histological Variants in Bladder CancerSarcomatoid Differentiation. Curr Med Chem 2014; 21(9):1117-1128.

6. Spiess PE, Tuziak T, Tibbs RF, Bassett R, Tamboli P, Brown GA et al. Pseudosarcomatous and sarcomatous proliferations of the bladder. Hum Pathol 2007; 38(5):753-761.

7. Nicolas MM, Nazarullah A, Guo CC. Sarcomatoid urothelial carcinoma with chondrosarcomatous differentiation of the ureter: a case report. Anal Quant Cytol Histol 2014; 36: 111-116.

8. Neogi S, Kariholu PL, Dhakre G, Gupta V, Agarwal N and Bhadani P. Malignant urothelial carcinoma of urinary bladder in a young child: A rare case report. Urol $\mathbf{J}$ 2013; 81: 888-890.

9. Sung MT, Wang M, MacLennan GT, Eble JN, Tan PH, Lopez-Beltran A et al. Histogenesis of Sarcomatoid Urothelial Carcinoma of the Urinary Bladder: Evidence for a Common Clonal Origin with Divergent Differentiation. J Pathol 2007; 211(4): 420-430.

10. Dhanya KS, Nambiar VR, Sasindran PR. A rare tumour with a rare presentation: A case of sarcomatoid variant of urothelial carcinoma arising from ureter. BMH Med J 2017;4(4):126-130

11. Williamson SR, Lopez-Beltran A, MacLennan GT, Montironi R, Cheng L. Unique clinicopathologic and molecular characteristics of urinary bladder tumors in children and young adults. Urol Oncol 2013; 31: 414-426. 
12. Wang J, Gilespie C, Kunadharaju R, Taimon GA, Enke C. Sarcomatoid urothelial carcinoma: a single center experience. World J Oncol 2011; 2:175-1180.

13. Venyo AK and Titi S. Sarcomatoid Variant of Urothelial Carcinoma (Carcinosarcoma, Spindle Cell Carcinoma): A Review of the Literature. ISRN Urol 2014; 20(14): 794798.

14. Wang Z, Xiong W, Pan C, Zhu L, Wang X, Huang Z et al. Aggressive muscle-invasive bladder cancer with sarcomatoid differentiation in a 10-year-old girl: a case report. Exp Ther Med 2016; 11(3): 985-987.

15. Resnick MJ, Bassett JC and Clark PE. Management of superficial and muscle-invasive urothelial cancers of the bladder. Curr Opin Oncol 2013; 25: 281-288.

16. Bujons A, Caffaratti J, Garat JM and Villavicencio H. Long-term follow-up of transitional cell carcinoma of the bladder in childhood. J Pediatr Urol 2014; 10 : 167-170.

17. Jacklyn YJ, Po YT, Puay HT, Chee YN, Lee LS. A Rare Case of Rectal Metastasis from Sarcomatoid Variant of Urothelial Carcinoma: A Case Report. Am J Cancer Case Reports 2015; 3(5):1-5.

18. Robinson SP, Farooq A, Laniado M, Motiwala H. The demographic features, clinical outcomes, prognosis and treatment options for patients with sarcomatoid carcinoma of the urinary bladder: a single centre experience. Int Braz J Urol 2018; 44(1): 45-52.

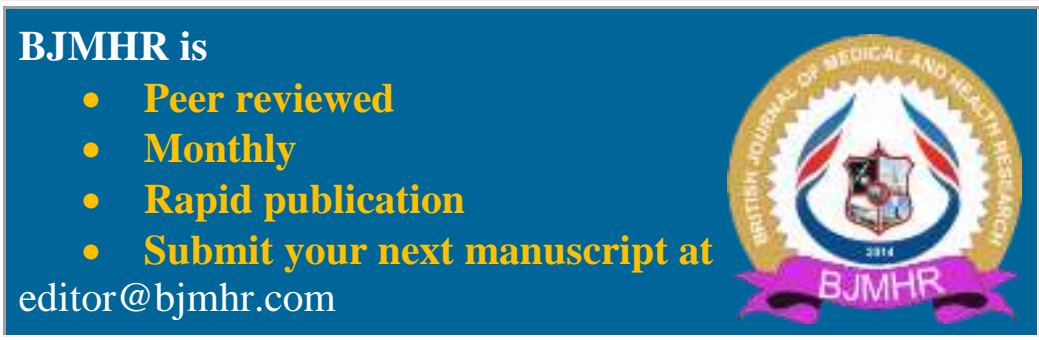

